\title{
Balanced Assessment of the Business Partner's Potential: Three-step Selection Procedure for the Sustainable Development of the Strategic Alliance
}

DOI: http://dx.doi.org/10.12775/JCRL.2016.014

\author{
RAFAє DREWNiAK \\ Faculty of Management, UTP University of Science and Technology \\ in Bydgoszcz, Poland \\ e-mail: drewniak@utp.edu.pl
}

\begin{abstract}
Negotiating a strategic alliance agreement is one of the essential determinants of the success of the entire agreement, and it is also the logical conclusion of the whole building process of the strategic alliance. At the same time, already at this step there is the relationships building process between partners and the need to further maintaining of the alliance. Therefore, a special attention should be paid to the negotiating process of a strategic agreement, conditioning the effectiveness of alliance management in the future as well as the scope and quality of relations between the allies. In fact in this phase of the strategic agreement takes place establishing the common strategy, which in turn determines the friendly start of the future cooperation. The aim of this study is to identify the key factors that determine building and sustaining friendly relations between enterprises and at the same time determine the success of the whole alliance. Considerations were based on the analysis of literature describing the theoretical framework of strategic alliances creation as well as business practices in this area. This allowed to propose a three-step process of selecting the potential company to the alliance, taking into account the profile analysis of the future ally, assessment of its resources and cultural and strategic fit. These issues make possible to ensure the sustainable development of the planned alliance and the success of partners companies. The selection and negotiations process is
\end{abstract}


crucial in maintaining lasting relationships with the allies. It should be foreseen whether the planned cooperation will not hinder or even prevent the alliance continuation in the future, or will cause unwillingness to enter into other cooperative agreements because of the mismatch of strategic partners or excessive cultural differences, and thus ineffective functioning of the alliance in the future.

Keywords: strategic alliance, partner selection, partners strategic fit, alliance formation.

\section{Introduction}

One of the fastest and most reliable ways to reach new sales markets and to raise the value of an enterprise is participation in a strategic partnership in a form of a strategic alliance. However, the success of partner enterprises, as well as of the entire alliance, depends on numerous factors. Among those, the following are named among others: the partners' strategic and cultural fit, complementarity of their contributions to the agreement, the scope of allocated duties, or the question of dividing expected profits (Cygler, 2009; Dyer and Singh, 1998, pp. 660-679). These conditions specify the concept and the scope of functioning of a planned alliance and at the same time they are the most important steps in forming the alliance. In this phase of creating a strategic agreement, the future common strategy is established, which in turn determines the commencement of a friendly cooperation (Drewniak, 2004, p. 191). Thus, reaching a consensus at the negotiation stage of creating a partnership agreement is a necessary condition for building favourable relations between the allies in the future. The areas where a conflict between parties may arise include, among others, disproportions in the current enterprise management structure, the necessity to withdraw from some markets and/or certain market segments, the loss of decision autonomy and others (Kale and Singh, 2000, pp. 217-237; Mohr and Spekman, 1994, pp. 135-152).

Therefore, precise selection of a potential partner enterprise for forming an alliance is essential for the allies' success and the success of the alliance. Negotiating a partnership agreement undoubtedly constitutes an essential determinant for the success of the entire agreement and at the same time it is a logical finalisation of the entire process of 
building it. Already at this stage relations between partners are formed and it is necessary to maintain those relations. Therefore, special attention needs to be paid to the process of selecting an enterprise for cooperation, which conditions the effectiveness of managing the alliance in the future as well as the scope and quality of relations between allies. When analysing the value of a potential ally, special attention needs to be paid to its size, competitive position, significance of its resources and capabilities, organisational structure and behaviour patterns as well as management competences (Gulati, 1995, pp. 619-652; Bierly and Gallagher, 2007, pp. 134-153).

Strategic alliances, as a way of external development of enterprises, went through a dynamic development in the 1980s and 1990s. Initial euphoria in realisation of the strategy of strategic alliances has been substituted by common sense and economic calculation. That was the result of concluding numerous unsuccessful agreements, which were caused by, among others, mistakes at the stage of selecting a partner for the alliance. Currently, creating strategic alliances is carried out more carefully and is based on methods which allow to reduce the risks related to concluding an agreement with an inappropriate enterprise. For this purpose, application of certain methods and procedures of selecting an ally for cooperation significantly reduces the risk of the alliance failing in the future. This article proposes a 3-stage procedure of selecting a partner enterprise for a strategic alliance that includes: partner profile analysis, strategic and cultural accommodation of partner enterprises and score-based analysis of the ally's potential.

\section{The process of forming a strategic alliance}

The concept of a strategic alliance is defined in various ways. We can assume that a strategic alliance is a special type of cooperation between at least two enterprises - including competition - operating in the same or related sectors with the objective of achieving common objectives agreed on earlier, by engaging core resources along with maintaining autonomy by each of them in the scope of spheres not included in a partnership agreement. A strategic alliance is therefore treated as an intermediate between competition and cooperation (Romanowska, 1997, pp. 11-14; Drewniak, 2004, p. 18; Badaracco, 1991, pp. 4-9; Aaker, 1993, pp. 320-322; Inkpen, 1998, pp. 69-73). 
Undertaking cooperation in a strategic alliance involves employing significant resources, therefore obtaining data and information on a potential partner becomes a necessity. Parties require reliable information on the economic and financial conditions, events or obligations, organisational structure, human resources and other - this information is used in negotiations of an agreement (Heimeriks, 2010, pp. 57-84; Cummings and Holmberg, 2012, pp. 136-159). In order to avoid domination of the agreement by one (stronger) partner, there should be a consensus concerning not only the size and strength of partners (conditions of the strategic fit), division of costs and profits from cooperation (area of economic fit) or specifying current operations (scope of operational fit), but also the awareness of needs, ethical conduct and other elements which constitute the area of cultural fit between partners of an alliance.

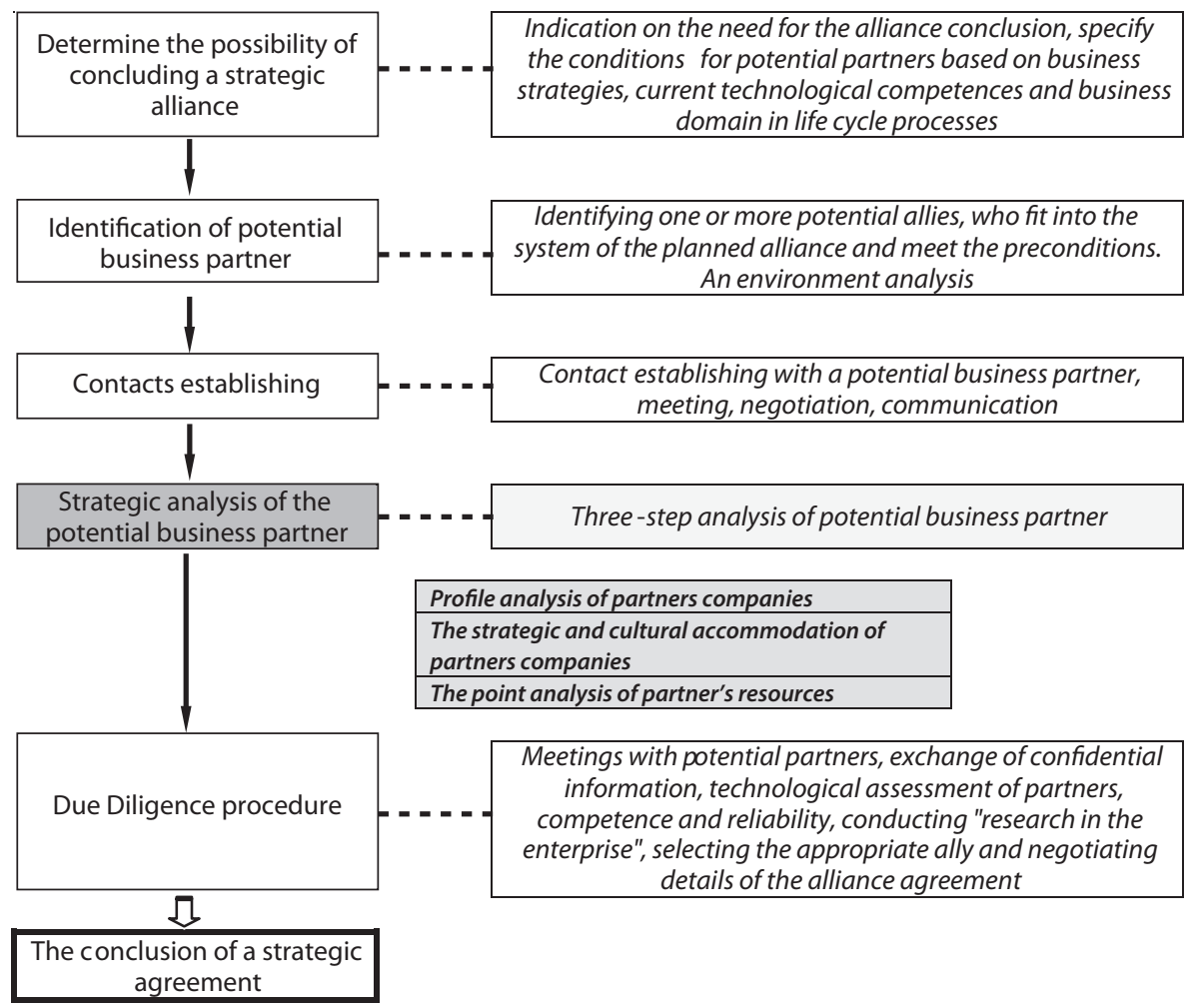

Figure 1. The process of forming a strategic alliance

Source: own work based on: Mitsuhashi, 2002, pp. 109-133. 
In this scope it is suggested that such attributes of partners as conduct and ethical system should be similar. Realisation of this task may cause various consequences and be the basis of growing conflicts in the future (Das, 2000, pp. 31-61; Kelly, Schaan and Joncas, 2002, pp. 11-22). Therefore, precise cultural fit between partners already at the beginning of cooperation can help the allies to achieve common objectives. In the process of forming an alliance and selecting a potential enterprise for cooperation a few stages can be distinguished (Figure 1).

The effect of inference of requirements set out to a potential partner enterprise should be creating a profile of a future partner in the scope of the abovementioned characteristics. One of the key stages before signing a cooperation agreement is conducting an analysis of a profile of potential partner enterprises, the scope of their strategic, cultural and economic fit and a score-based assessment of resources. Apart from analysing the broader surroundings and competition, it is research that allows making a rational decision concerning the selection of the most suitable ally for an agreement.

\section{Profile analysis of a potential partner enterprise for a strategic alliance}

Due to the fact that the key criteria of selecting an enterprise for an alliance should be mainly the conditions and specificity of the future agreement, there are three fundamental conditions that a potential ally for an alliance should fulfil (Lewis, 1990, pp. 266-268):

- sufficient level of competitiveness and market power,

- contribution of complementary and balanced resources to the alliance,

- showing engagement in realisation of common objectives of the agreement.

Requirements set out for candidates for an alliance should be varied in terms of the type of domain in which the enterprise operates, the ally's objectives, its competitive position and market power as well as other criteria depending on the character of a planned alliance. However, there are several unified conditions that should be considered when selecting a strategic partner, regardless of the type and character of the alliance. A common vision of a planned undertaking is essential in this scope. In a situation where there are significant discrepancies between 
potential allies, concerning the way of functioning on the market, the vision of cooperation and the term of the alliance, realisation of common objectives can encounter problems which will make it impossible to achieve success of the planned agreement (Emden, Calantone and Droge, 2006, pp. 299-389; Whipple and Frankel, 2000, pp. 21-28; Das and Kumar, 2009, pp. 24-52). Therefore, before an alliance is formed one should agree whether the enterprises declaring the will to cooperate treat the alliance as a long-term undertaking, which later can be extended, or as a chance to utilise a particular market opportunity potentially terminating the alliance. An extremely important condition for a successful future agreement is a consensus in terms of strategic objectives of both partners, which in turn result from a common vision of the alliance (Kauppila, 2010, pp. 283-312; Das and Kumar, 2009, pp. 24-52). The result of conducting inference of requirements set out for a potential partner for an alliance should therefore be creation of a profile of a future partner, which would characterise the most important conditions for the success of the future agreement. This concerns especially such characteristics as mission, strategy, organisational structure, organisational culture and the character of competitive activities. Figure 2 presents an example analysis of a profile of a partner enterprise for a strategic alliance.

\begin{tabular}{|c|c|c|c|}
\hline Criteria & Compatibility & Ability to adapt & Non-compliance \\
\hline Mission & $\Delta \ldots .$. & & $\Delta$ \\
\hline Strategy & 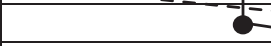 & $-\cdots\rangle$ & $\Delta$ \\
\hline \multicolumn{4}{|c|}{ Organisational structure } \\
\hline Culture & $\Delta--$ & & $\underset{0}{0}$ \\
\hline Resources & $\Delta^{\prime}$ & & $\triangle$ \\
\hline Alliance goals & $\Delta$ & $\triangle$ & \\
\hline
\end{tabular}

Figure 2. An analysis of a profile of potential partner enterprises for a strategic alliance Source: Chwistecka-Dudek and Sroka, (2000), p. 115.

The example profile presented in Figure 2 shows a compliance of different candidates to form an alliance in terms of specific behaviours (criteria). From the three companies the most suitable partner seems to be company A, whose most characteristics coincide with characteristics of the enterprise searching for an ally for a strategic alliance. There is a conformity in terms of the mission, organisational culture 
of the enterprises and the objectives of the planned alliance. Whereas discrepancies in terms of strategy and organisational structure can be eliminated during negotiations of the agreement or during the term of the agreement. Undertaking cooperation with the other enterprises does not portend well for successful cooperation, because of diagnosed (at this stage) too large discrepancies between the characteristics of the enterprises. However, one needs to consider the fact that enterprises $\mathrm{B}$ and $\mathrm{C}$ could become an ally in a planned alliance after conducting further analysis. That is because the next stages are: analysis of cultural fit of potential allies and score-based assessment of their resources. This analysis can significantly influence the decision on selecting a future cooperating party and in the process it compensates the shortages pointed out by the analysis of the profile of potential partner enterprises.

\section{The importance of cultural and strategic fit in a strategic alliance}

Establishing the scope of an alliance is based on three essential selection criteria and the scope of negotiations between partner enterprises (Doz and Hamel, 2006, p. 113): strategic interests, net profit and common operations. The first area of interest determines the strategic fit of the partners and includes the broadest spectrum of analyses. Profit constitutes the essence of economic scope of functioning of the planned agreement, whereas common operations determine the operational scope of actions of the subjects.

Strategic scope of an alliance should be precisely specified while selecting a partner and should be negotiated before the agreement is concluded. When executing a partner agreement, which contains previously unsettled conflicts in this scope, partners can achieve less favourable and not proportional benefits, which in turn can undermine the effectiveness of the alliance. Therefore, it is an important task for the alliance managers to minimise the conflict between partners' expectations and the strategic scope of the planned alliance. The scope of strategic decisions at this stage is especially significant in the case of cooperation based on combining competences. It is a misconception of strategic scopes of partners or trivialisation of this issue while selecting an ally which can become insurmountable during the term of the alliance in the future. However, on the other hand, enterprises which as a result of a strategic alliance attempt to obtain new abilities 
based on knowledge and competences transfer, have less problems with determining the scope of a strategic alliance, especially when they operate on different markets or segments thereof. Each of the partners will have different strategic objectives towards their own operation areas (markets) and will learn from their partner. Whereas in alliances built on the basis of integrating partners' strengths, the strategic scope of the agreement should not constitute the source of conflict. Otherwise, disproportions in terms of the strategic scope will most likely make it impossible to conclude such an agreement ${ }^{1}$.

Operational scope of the alliance includes current operations within the frame of the alliance and actual operations jointly run by partner enterprises. In the process of selecting and negotiating a partner agreement the interested parties can decide to minimise or maximise the operational scope of the alliance. The first alternative reduces the necessity to coordinate and integrate operations, which in turn can be reflected in savings on travelling costs, accordance, combined teams etc. This can be achieved by an agreement to commence a part of operations within the frame of the alliance (at least at the beginning of joint cooperation) alone (by oneself) by each partner (Doz and Hamel, 2006). Thanks to this, there is also reduced the risk of an unwanted transfer of technology and know-how to the partner, which very often is the competition (this concerns especially alliances which combine competences of allies). On

1 An example of the process of fitting the strategic scope for partners can be the alliance concluded between GE and SNECMA, which was based on creating benefits of combining unique and specific values. The scope of cooperation concerned production of engines, fuselages, turbines and fans for jet airplanes. GE perceived the creation of the alliance with a European manufacturer of airplane fuselages (France) as a way to avoiding and afterwards opposing the domination of Pratt\&Whitney in the USA, the leader in the field of engines for civilian airplanes. Whereas the French partner perceived the cooperation as an opportunity to enter the market of civilian airplanes and to obtain credibility, which GE had with Boeing and McDonnell Douglas (leading manufacturers of civilian jet planes). The strategic scope of the alliance included the entirety of operations related to jet engines, civilian and military. Engines were designed in the same laboratories, produced in the same plants, whereas decisions of the line organisation (product concepts) were made in relation to not only one of the partner's markets, but with consideration of both areas. The success of the alliance was undoubtedly determined by detailed arrangements and negotiations concerning the strategic scope before concluding the agreement. Therefore, the success of an alliance based on combining competences must take into consideration the uniqueness of contributions from each partner, and their scope should be discussed in detail during the negotiations of a partner agreement. See: Doz and Hamel, 2006, pp. 99-102, 113-116. 
the other hand, minimisation of the operational scope can turn out costly, especially if the alliance operations get wider in the future. Whereas a wider operational scope usually allows for a wider range of transfer of resources between partners. Thanks to this it is easier to establish new contacts, communicate and learn together by exchanging knowledge, competences and experience ${ }^{2}$.

Analysing the profile of a potential ally requires paying attention to the extent of synergy or strategic fit of partners and the extent of cultural fit. The importance of the strategic and cultural accommodation of potential alliance parties is presented in Figure 3.

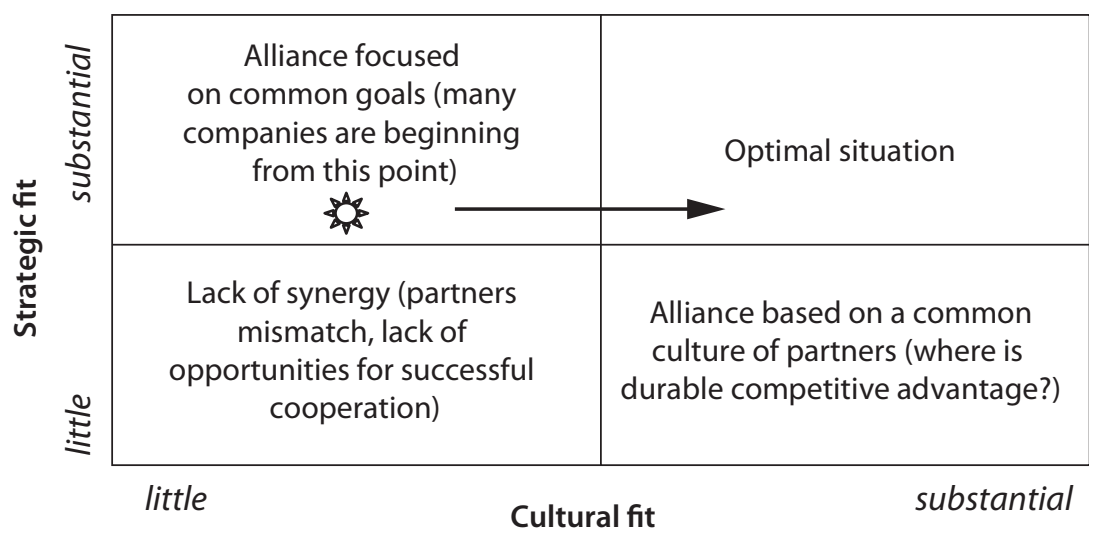

Figure 3. Strategic and cultural accommodation of potential alliance partners Source: Faulkner and Bowman, (1996), p. 127.

The necessary condition, which substantiates the commencement of a strategic alliance, is strategic fit between partners, which proves complementarity of both parties (Volkokari and Helander, 2007, pp. 597-608; Murray and Kotabe, 2005, pp. 1525-1533). However,

2 For example, the alliance between AT\&T and Olivetti initially assumed a form of a series of short-term contracts for mutual supplies (partners exchanged existing products). Thanks to this the cooperation was limited to periodic arrangements and negotiations in terms of prices and supply conditions. An attempt to create a line of microcomputers together failed because of the atmosphere of distance, lack of trust and mutual suspicions. The initial form of cooperation caused conflicts between partners and undermined the process of obtaining knowledge, among others, leading to a competitive character of cooperation and undermining the sense of continuation of the alliance. See: Doz and Hamel, 2006, pp. 39-40, 117-118. 
surviving an alliance and its effective functioning also depend on cultural compliance. Cultural and strategic fit of partner enterprises allows to qualify the agreement to the top, right quarter of the matrix in Figure 3. It is an optimal initial situation to create a strategic alliance, where both strategic and cultural fit exist for both parties. Whereas, the lack of concordance in terms of strategic and cultural fit does not provide perspective of success for the planned agreement. A consensus in one of the discussed areas gives a chance for creating an alliance, even though cooperation is difficult in this case. For example, an analysis of capabilities (profile) of partner B, performed earlier, in Figure 2 proves that there is strategic fit between potential partners, however there is no concordance in the cultural aspect. Therefore, it is an alliance oriented towards common objectives. Certainly, in order for a strategic alliance to be characterised by high effectiveness and continuity of functioning the allies should aim at achieving a fit both in the strategic and cultural dimensions. Supplementing this balance with the economic scope gives a chance to find a source of constant competitive advantage of the alliance on the market. In fact, partners have more confidence in each other when trust among partners is high, and thereby the probability of partners opportunistic behaviour decreases (Bierly and Gallagher, 2007, pp. 134-153).

\section{Score-based analysis of resources of a potential partner enterprise for an alliance}

Selection of potential partners should not be solely based on informal contacts and by using personal contacts which senior management keeps with managers from other enterprises. Selection of an ally for an alliance without conducting a fit analysis of a partner may turn out to be a risky decision both for the created agreement as well as for the enterprise itself. At the selection stage and assessment of a partner for an alliance one should not reject the possibility of reaching an agreement with the competition, suppliers or companies operating in related sectors, as each of them can contribute valuable advantages to the agreement. Among the methods used for assessment of capabilities of a future ally, a versatile and comprehensive model is used, based on which a score-based analysis of resources of a potential partner enterprise is conducted (Harvey and Lusch, 1995, pp. 195-212; Cummings 
and Teng, 2006, pp. 1-18). An analysis of a partner enterprise itself is mainly based on identifying economic, organisational and technological potential, which is at the disposal of the enterprise, its main objectives, operation philosophy or organisational culture. This mainly concerns the degree of strategic synergy of partners and the scope of cultural fit of the partners. At the same time, the enterprise which conducts an analysis of a potential ally for an alliance must be aware of its own competences and capabilities, otherwise it will not be able to determine what fit will be optimal for it and for the built alliance (Mason, 1993, pp. 10-15; Cummings and Teng, 2006, pp.1-18). Analysing a partner for the purpose of an alliance should be conducted from the perspective of benefits that it can contribute to the future agreement (e.g. unique products, competitive position, favourable price structure, abilities and competences of employees etc.). Those attributes can have both a material character and non-material character. The first group (tangible benefits) includes, among others, significant values present in particular value links of the value chain (e.g. R\&D sphere, production potential, financial capabilities). Non-material benefits are also of some significance, which are especially important in the long-term of a planned agreement, as an analysis of only material assets of a partner enterprise makes it possible to assess short-term benefits (Das and Kumar, 2009, pp. 24-52; Kok and Creemers, 2008, pp. 472-487). At the same time, during the term of an alliance these capabilities will be, to a larger or lesser extent, obtained by the partners. The non-material potential of a partner, especially its attributes, among others, in the scope of capabilities in the marketing, organisation and management sphere, know-how, strategic orientation or organisational culture (internal non-material attributes), as well as clients' loyalty, relations with local authorities, suppliers etc. (external non-material attributes), can often determine the selection of a suitable ally, and at the same time determine the success of a strategic alliance in the future. Figure 4 presents an analysis scheme of a potential partner enterprise for a strategic alliance and it characterises key aspects (attributes), which should be considered when selecting a suitable candidate for the planned agreement. 


\begin{tabular}{|c|c|c|c|c|}
\hline $\begin{array}{l}\text { Factor } \\
\text { weight }\end{array}$ & $\begin{array}{l}\text { Factors characterizing the part- } \\
\text { ner's company (CF-compensatory } \\
\text { factors) }\end{array}$ & \multicolumn{2}{|l|}{ Rating } & $\begin{array}{l}\text { Contribution } \\
\text { to the success } \\
\text { of the alliance }\end{array}$ \\
\hline \multicolumn{5}{|c|}{ Material resources (tangible) } \\
\hline $\mathrm{W}_{1}$ & Capital & low & 1-5 high & $\mathrm{CF}_{1} * \mathrm{~W}_{1}$ \\
\hline $\mathrm{W}_{2}$ & Production abilities & weak & 1-5 high & $\mathrm{CF}_{2} * \mathrm{~W}_{2}$ \\
\hline $\mathrm{W}_{3}$ & Location of the production & weak & 1-5 excellent & $\mathrm{CF}_{3} * \mathrm{~W}_{3}$ \\
\hline $\mathrm{W}_{4}$ & Technology & weak & 1-5 excellent & $\mathrm{CF}_{4} * \mathrm{~W}_{4}$ \\
\hline $\mathrm{W}_{5}$ & Company’s brand & weak & 1-5 excellent & $\mathrm{CF}_{5} * \mathrm{~W}_{5}$ \\
\hline $\mathrm{W}_{6}$ & $\mathrm{R}+\mathrm{D}$ expenditure & little & 1-5 high & $\mathrm{CF}_{6} * \mathrm{~W}_{6}$ \\
\hline $\mathrm{W}_{7}$ & The relative potential of the company & weak & 1-5 high & $\mathrm{CF}_{7} * \mathrm{~W}_{7}$ \\
\hline 1,0 & & & & \\
\hline
\end{tabular}

Non-material resources (intangible) within the company

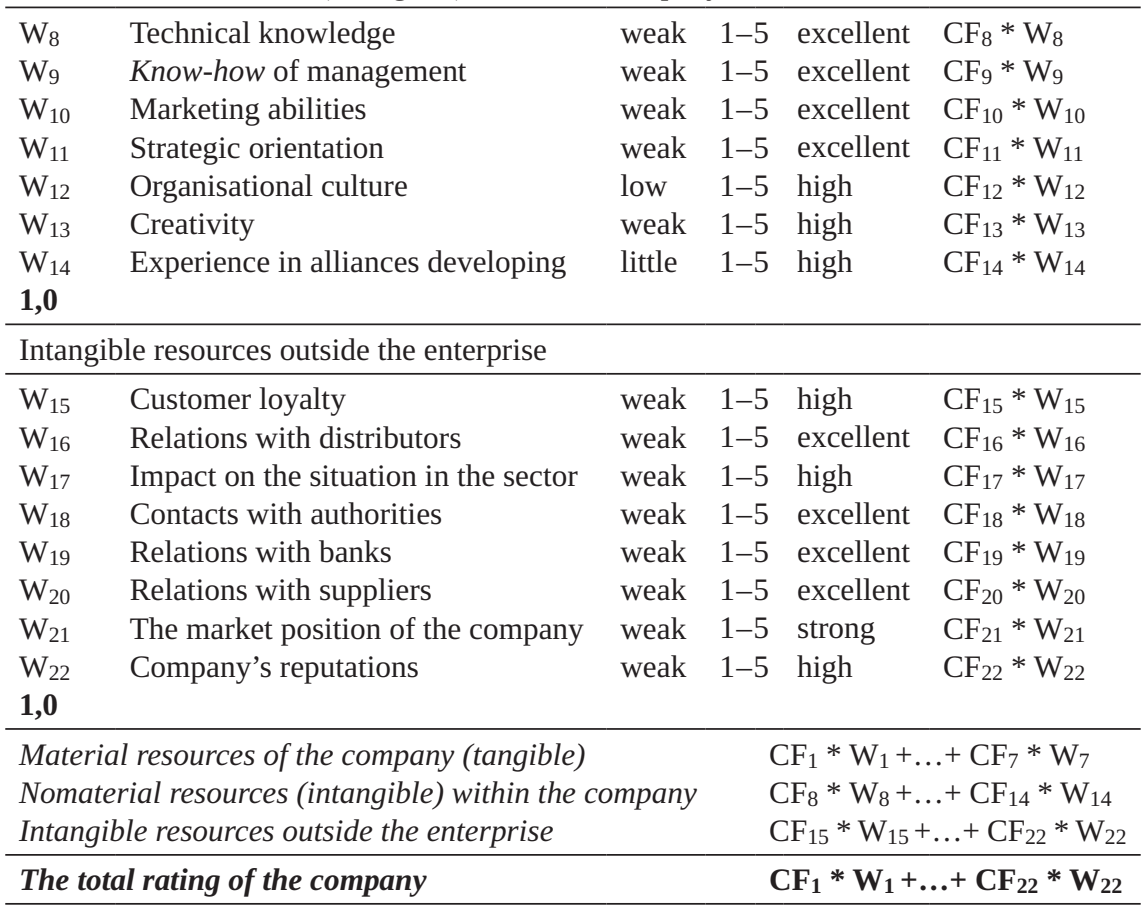

Figure 4. Score-based analysis method of the resources of a potential partner enterprise for a strategic alliance

Source: Harvey and Lusch, (1995), pp. 195-212; Sroka, (1996), p. 23. 
The specificity of factors used in an assessment of a potential enterprise for an alliance is their mutual counterbalance, which means that a low value of one of them can be compensated with an appropriately higher value of another (Cummings and Holmberg, 2012, pp. 136-159). The procedure of selecting an ally is carried out in two stages. First, there is identification of material (tangible) attributes of a partner, and afterwards the non-material (intangible) aspects of its operation and surroundings are determined. The weight of individual characteristics established earlier for an enterprise is multiplied by its assessment. The product obtained in this way constitutes the result of individual groups of analysed attributes. This result can reach the maximum of 5 points or the minimum of 1 point. This means that the assessment of the whole enterprise will fall between 3 and 15 points.

\section{Conclusion}

The presented procedure of selecting a partner enterprise for a planned alliance is one of many possible methods of assessing a candidate in terms of its usefulness for an alliance. Certainly, it can be stated that this method does not determine the success of an alliance in the future, however, it allows to reduce the risk related to selecting and concluding an alliance with a wrong partner. Furthermore, the multi-criteria character of the proposed procedure favours ensuring a balanced assessment and can, in the decisive scope, influence the development of an alliance in the future. In this understanding, applying a uniform method of analysis and selection of an ally allows to select the one that to the largest extent can contribute to the alliance success and which the strategic synergy and cultural fit are the largest. The initial list of partner enterprises potentially suitable for an alliance can constitute those which possess significant and complementary resources and access to desirable areas of operation (Bierly and Gallagher, 2007, pp. 134-153; Cummings and Holmberg, 2012, pp. 136-159). However, the process of selecting an ally requires not only a detailed analysis in the scope of the strategic fit, but also puts emphasis on identifying the objectives of a potential partner and the honesty of their intentions (Mohr and Sengupta, 2002, pp. 282-301). The indisputable awareness of each party's interest is the key element conditioning the success of a future agreement. Many strategic alliances are concluded for the purpose of obtaining the sought 
and indispensable capabilities, however it is recommended that it does not lead to becoming dependant on the partner enterprise, but rather to perceiving a planned joint undertaking as an organisational process of mutual learning about your partner. On this account, the alliance partners, characterised by complementary resources seem to be the most suitable, as you get the opportunity to combine and/or exchange technologies, which results from various competences of allies in order to create capabilities that are completely new and essential for the enterprises (Luffman, Lea, Sanderson and Kenny, 1996, pp. 167-168). The process of selecting and negotiating as well as the factors that determine it are of essential significance in maintaining long-lasting relations with allies. Therefore, there should be an attempt at predicting whether a planned cooperation through strategic mismatch of partners or excessive cultural differences, and at the same time ineffective functioning of an alliance in the future, do not hinder the alliance or even make it impossible to continue the alliance in the future, or it might cause aversion to concluding other cooperation agreements.

\section{References}

Aaker, D.A. (1993), Strategic Market Management, John Wiley \& Sons, New York.

Badaracco, J.L. (1991), The Knowledge Link: How Firms Compete Through Strategic Alliances, Harvard Business School Press, Boston.

Bierly, P.E., Gallagher, S. (2007), “Explaining Alliance Partner Selection: Fit, Trust and Strategic Expediency”, Long Range Planning, Vol. 40, pp. 134-153.

Chwistecka-Dudek, H., Sroka, W. (2000), Alianse strategiczne: Problemy teorii i dylematy praktyki, Profesjonalna Szkoła Biznesu, Kraków.

Cummings, J.L., Holmberg, S.R. (2012), "Best-fit Alliance Partners: The Use of Critical Success Factors in a Comprehensive Partner Selection Process”, Long Range Planning, Vol. 45, pp. 136-159.

Cummings, J.L., Teng, B.S. (2006), “The Keys to Successful Knowledge Sharing”, Journal of General Management, Vol. 31, pp. 1-18.

Cygler, J. (2009), Kooperencja przedsiębiorstw: Czynniki sektorowe i korporacyjne, Oficyna Wydawnicza SGH, Warszawa.

Das, T.K. (2000), “A Resource-based Theory of Strategic Alliances”, Journal of Management, Vol. 26, No. 1, pp. 31-61.

Das, T.K., Kumar, R. (2009), "Interpartner Harmony in Strategic Alliances: Managing Commitment and Forbearance”, International Journal of Strategic Business Alliances, Vol. 1, pp. 24-52.

Doz, Y.L., Hamel G. (2006), Strategic Alliances: The Art of Profiting through Cooperation, Helion-One Press, Gliwice.

Drewniak, R. (2004), Rozwój przedsiębiorstwa poprzez alians strategiczny: Cele i uwarunkowania w praktyce polskiej, TNOiK, Toruń. 
Dyer, J.H., Singh, H. (1998), “The Relational View: Cooperative Strategy and Sources of Interorganizational Competitive Advantage”, Academy of Management Review, Vol. 23, No. 4, pp. 660-679.

Emden, Z., Calantone, R.J., Droge, C. (2006), “Collaborating for New Product Development: Selecting the Partner with Maximum Potential to Create Value”, Journal of Product Innovation Management, Vol. 23, Issue 4, pp. 299-389.

Faulkner, D., Bowman, C. (1996), Strategie konkurencji, Gebethner i Ska, Warszawa.

Gulati, R. (1995), "Social Structure and Alliance Formation Patterns: A Longitudinal Analysis”, Administrative Science Quarterly, Vol. 40, No. 4, pp. 619-652.

Harvey, M.G., Lusch, R.P. (1995), “A Systematic Assessment of Potential International Strategic Alliance Partners”, International Business Review, Vol. 4, No. 2, pp. 195-212.

Heimeriks, K.H. (2010), “Confident or Competent? How to Avoid Superstitious Learning in Alliance Portfolios”, Long Range Planning, Vol. 43, pp. 57-84.

Inkpen, A. (1998), "Learning and Knowledge Acquisition through International Strategic Alliances”, The Academy of Management Executive, Vol. 12, No. 4, pp. 69-73.

Kale, P., Singh, H., Prerlmutter, H. (2000), "Learning and Protection of Proprietary Assets in Strategic Alliances: Building Relational Capital”, Strategic Management Journal, Vol. 21, pp. 217-237.

Kauppila, O. (2010), “Creating Ambidexterity by Integrating and Balancing Structurally Separate Interorganizational Partnerships”, Strategic Organization, Vol. 8, No. 4, pp. 283-312.

Kelly, M.K., Schaan, J.L., Joncas, H. (2002), “Managing Alliance Relationships: Key Challenges in the Early Stages of Collaboration”, $R \& D$ Management, Vol. 32, Issue 1, pp. 11-22.

Kok, R.A.W., Creemers, P.A. (2008), “Alliance Governance and Product Innovation Project Decision Making”, European Journal of Innovation Management, Vol. 11, No. 4, pp. 472-487.

Lewis, J. (1990), Strategische Allianzen, Campus Verlag, Frankfurt-New York.

Luffman, G., Lea, E., Sanderson, S., Kenny, B. (1996), Strategic Management: An Analytical Introduction, Blackwell Business, Oxford.

Mason, J.C. (1993), “Strategic Alliances: Partnering for Success”, Management Review, Vol. 82, No. 5, pp. 10-15.

Mitsuhashi, H. (2002), "Uncertainty in Selecting Alliance Partners: The Three Reduction Mechanism and Alliance Formation Processes”, The International Journal of Organizational Analysis, Vol. 10, No 2, pp. 109-133.

Mohr, J.J., Sengupta, S. (2002), “Managing the Paradox of Inter-firm Learning: The Role of Governance Mechanisms”, Journal of Business and Industrial Marketing, Vol. 17, Issue 4, pp. 282-301.

Mohr, J., Spekman, R. (1994), “Characteristics of Partnership Success: Partnering Attributes, Communication Behavior and Conflict Resolution Techniques”, Strategic Management Journal, Vol. 15, Issue 2, pp. 135-152.

Murray, J.Y., Kotabe, M. (2005), "Performance Implications of Strategic Fit Between Alliance Attributes and Alliance Forms”, Journal of Business Research, Vol. 58, Issue 11, pp. 1525-1533.

Romanowska, M. (1997), Alianse strategiczne przedsiębiorstw, PWE, Warszawa.

Sroka, W. (1996), "Podejście systemowe w badaniu potencjalnych partnerów do aliansów strategicznych”, Przeglq̨d Organizacji, No. 10, p. 23. 
Volkokari, K., Helander, N. (2007), “Knowledge Management in Different Types of Strategic SME Networks”, Management Research News, Vol. 30, Issue 8, pp. 597-608.

Whipple, J.M., Frankel, R. (2000), “Strategic Alliance Success Factors”, Journal of Supply Chain Management, Vol. 36, Issue 2, pp. 21-28. 